\title{
An Investigation of Nurses Perception of the Organizational Power in the Paediatric Ward- Based on the King Model
}

\author{
P. Delnavaz ${ }^{1}$, M.H. Sahebihagh², S. Valizadeh³ ${ }^{3}$ M. Jasemi', S. Rezaee ${ }^{5}$, M.A. Bostanabad6
}

\begin{abstract}
${ }^{1}$ Department of Paediatric Nursing, Midwifery Tabriz University of Medical Sciences, Tabriz, Iran. ${ }^{2}$ Department of Community Health, Tabriz University of Medical Sciences, Tabriz, Iran. ${ }^{3}$ Department of Paediatric Nursing, Tabriz University of Medical Sciences, Tabriz, Iran. ${ }^{4}$ Department of Nursing, Tabriz University of Medical Sciences, Iran.

${ }^{5}$ Department of Nursing, Urmia Branch, Islamic Azad University, Urmia, Iran.

${ }^{6}$ Department of Paediatric Nursing, Tabriz University of Medical Sciences, Tabriz, Iran.
\end{abstract}

\section{ABSTRACT}

\section{BACKGROUND}

The organizational power in nurses makes them function more professionally, increasing their job satisfaction. Hence, a good understanding of this issue can have a significant effect. We wanted to investigate the nurses' perception of organizational power in the paediatric wards.

\section{METHODS}

This descriptive study was carried out in 2017 in the paediatric ward of Motahari Hospital in Urmia. A total of 175 nurses were recruited and studied using the organizational power questionnaire developed by Sieloff-King. Validity of the questionnaire was assessed using content validity, while its reliability was assessed using Cronbach's alpha, which was 0.89. Pearson's correlation test was also carried out to determine the relationship between the demographic variables and nurses' perception of organizational power.

\section{RESULTS}

The results showed that $52.52 \%$ of nurses had a good perception of organizational power, while overall perception of organizational power was $127.75 \pm 17.99$. As far as the items in the power subsets are concerned, the highest score was gained by role play and the position of the nursing group. The lowest score was also obtained by the resource and environmental factors. Furthermore, there was an inverse relationship between age and position subsets, and younger nurses had better perception of this issue.

\section{CONCLUSIONS}

Based on the results of this study, it is necessary to set the scene for nurses to get more acquainted with the organizational power and its effect on the quality of health care. It is also necessary to improve nurses' perception of the organizational power and the nursing frameworks and models as part of an appropriate approach.
Corresponding Author: Dr. Mohammad Arshadi Bostanabad, Department of Paediatric Nursing, Faculty of Nursing and Midwifery, Tabriz University of Medical Sciences, Iran. E-mail: arshadi_m@yahoo.com

\section{DOI: 10.14260/jemds/2019/737}

Financial or Other Competing Interests: $\mathrm{Dr}$. Arshadi Bostanabad reports grants from Tabriz University of Medical Sciences, outside the submitted work.

\section{How to Cite This Article:}

Delnavaz P, Sahebihagh MH, Valizadeh S, et al. An investigation of nurses perception of the organizational power in the paediatric ward- based on the king model. J. Evolution Med. Dent. Sci. 2019;8(45): 3397-3402, DOI:

\section{KEY WORDS}

Paediatric Ward, Nursing, Organizational Power, King Model 


\section{BACKGROUND}

Power is inevitable in organizations( ${ }^{(1)}$ as there is no society and organization without power. The realization of organizational goals is contingent upon power, and managers need power to effectively play their role in the organization. ${ }^{(1,2)}$ There are different approaches to and definitions of power.(3) Power originates from the organizational status of individuals.(4) It can be potentially assumed that everyone in power can have an effect on an individual or a group.(5) Grieftin and Moorhad defined power as the ability to do the work according to one's will. Power is a natural process.(6) It is taken into account in various disciplines and has received a special attention in nursing, as an abstract concept for most nurses. (7) It also has implications for health policies, organizational structure, and nursing practices.(8) Nurses need power to succeed in the organization and play the roles of caring, treating, and communicating properly with their authorities and colleagues. Empowering nurses makes them more committed to their duties in the organization and care system and helps them work more professionally.(9) Power in nurses leads to high participation, flexibility, and success in the care system.(10) In fact, power is the determinant of job satisfaction,(11) as a lack of a sense of power and a negative nursing attitude to power cause frustration and dissatisfaction.(12) As a result, others decide on nursing.

Although Sieloff believes most nursing groups have power, they often appear to be health care system theorists given the social status of the physicians. However, nurses, unlike physicians, are not able to comment at the organizational level.(13,14) Considering the importance of power, studies show that in health care settings, power is in the hands of a particular group and nurses are often dominated by that group, $(7,15)$ resulting in disability and negative effects on the care quality and job satisfaction.(16) Since nurses' position is not well defined and understood in Iran, the use and understanding of the nursing power is a must.(17,18) A proper understanding of power is one of the ways in which nursing work can progress and goals can be realized.(11,19) However, the misunderstanding of power by nurses leads to a negative perception and a sense of powerlessness and inefficiency in nurses and has side effects on the organization and organizational goals.

The benefits of power for the organizations, especially the hospital system, and its importance in achieving organizational success, especially for success in the care system, have not been addressed in the nursing profession despite the need for further clarifications.(20) One way of clarifying these points it to use the nursing frameworks and models. The Emotion King model is one of the models of organizational power. This mode, which was introduced in 1981 , is one of the most important and best-known models of power in the field of nursing. In this model, King refers to a systematic approach to the evolution of the systemic framework of the theory of goal achievement, and believes that knowing the complex and dynamic behaviours of human beings in different nursing situations leads to the formation of a conceptual framework and the individual, interpersonal and social systems in the field of nursing. Each of these three systems considers human beings to be the core of the system.
The concept of the human metaparadigm in King's system is expressed in terms of a personal, interpersonal, and social system while each one has multiple dimensions. The concept of the personal system includes perception, self, mental image, growth and evolution, time, space, and learning. The concept of an interpersonal system consists of communication, interaction, exchange, roles, stress, and coping. The concept of a social system includes the organization, authority, power, dignity, and decision-making notions. Power, which is one of the dimensions of King's social system, is described as a situation in which individuals take action in a manner consistent with and against their will. King has paid special attention to the importance of power in nursing and the achievement of the goals of this group. King considers the nurses' perception of power to be essential in the identification of the sources of power and attainment of organizational goals. He categorizes power into eight subcategories, namely control and domination of environmental factors, the role of the nursing group in the organization, the available resources, the ability of the nursing group to achieve goals, proper communication, the power perspective and effective power of supervisors and superintendents in achieving goals. (11,19)

Considering the importance of power and nurses' perception of power in their empowerment and the need for clarifying the concept of power from King's perspective, this study aimed to determine nurses' perception of organizational power in nursing profession and its relationship with individual variables based on the concept of power in King's model.

\section{METHODS}

This 2017 descriptive study was an attempt to assess nurses' perception of the power of the nursing group in the care system using King Model and nurses in the paediatric ward of Shahid Motahari Hospital in Urmia. In this study, 159 nurses were selected for assessing nurses' perceptions based on the findings reported by Valizadeh et al.'s (2012). (11)

$$
\mathrm{n}=\frac{\mathrm{pqz}}{\mathrm{d} 2} \frac{211.72 \times 88 \times 1.96^{2}}{0.05^{2}}=158.98 \cong 159
$$

Since 200 nurses were working in the Motahhari Hospital at the time of the study, all eligible nurses were recruited for this study using the census method. Finally, of the 200 distributed questionnaires, 180 were collected and 5 were ruled out because only $20 \%$ of the questions were answered. Finally, 175 questionnaires were examined. The nurses selected for this study had a bachelor's or master's degree and were working in one of the internal wards or surgery wards of the hospital. After obtaining the permission of the vice president of the research and ethics committee of the university (code: IR.TBZMED.REC 1326.1395) and winning the approval of Tabriz University of Medical Sciences, arrangements were made by the educational deputy of the Nursing and Midwifery Faculty of Tabriz and the consent of the authorities of the Educational and Treatment Center of Shahid Motahari Hospital of Urmia was gained. Thereafter, 
sampling was started on April 4, 2017. The researcher visited the paediatric wards of Motahari Hospital and asked the nurses to complete the organizational power questionnaire at the appropriate time. Otherwise, they could take the mentioned questionnaire with them and deliver them in the next shift. In order to assess the nurses' perception of organizational power in the care system, King model of organizational power questionnaire was used: SKAGPO (Sieloff-King Assessment of the Group Power within Organization). The questionnaire was prepared by Sieloff and King in 2000 and its validity and reliability were studied in different countries for several consecutive years. Moreover, the validity of the organizational power questionnaire was assessed by Valizadeh et al. in Tabriz in 2012. Therefore, it was considered as a valid tool in this study(11) and the questionnaire was re-examined using the content validity method. Cronbach's alpha method was employed in this investigation to determine the reliability of the questionnaire and the resulting reliability coefficient was 0.89 . The King's organizational power questionnaire had two parts. The first part included questions about the demographic characteristics of the participants, and the second part contained 36 questions in different fields: 7 items about controlling the environmental factors, 4 items about position, 3 items related to role play, 6 items about resources, 3 items about appropriate communication, 4 items about the competence of the supervisors, 4 items related to goal achievement, and 5 items about the power prospect. This questionnaire was previously translated into Persian by Valizadeh et al. This questionnaire was developed based on the Likert scale with 5 options $(5=$ totally agree, $4=$ agree, $3=$ no idea, $2=$ disagree, and $1=$ totally disagree) and the overall score of nurses' perceptions of the organizational power was between 180 and 36. Accordingly, the participants' scores in the study were divided into three levels of poor relation (36$80)$, moderate relation (81-125), and a strong relation (126180). Data were analysed in SPSS 21.

The descriptive statistics (frequency, mean, and standard deviation) were used to describe the data, while the relationships of the demographic variables with nurses' perception of organizational power were explored using Pearson's correlation. Finally, the T test and ANOVA (analysis of variance) were carried out to compare the mean scores of perceptions of organizational power based on demographic characteristics.

\section{RESULTS}

A total of 175 nurses were evaluated. The mean age of the employed nurses was $28.48 \pm 5.57$ years and their mean working experience was $5.09 \pm 4.86$ years. On average, they had taken care of $9.55 \pm 3.06$ patients. In this study, it was found that nurses had $76.98 \pm 19.31$ hours of physical over time on average in addition to their obligatory shifts. Other demographic characteristics are shown in Table 1. In a survey of nurses' perception of nursing organizational power, the results showed that $52.5 \%$ of nurses had a good perception (Table 2).

\begin{tabular}{|c|c|c|}
\hline Variable & \multicolumn{2}{|c|}{ Percentage (Frequency) } \\
\hline \multirow{2}{*}{ Sex } & Male & $2(1.1)$ \\
\cline { 2 - 3 } & Female & $173(98.9)$ \\
\hline \multirow{2}{*}{ Marital status } & Single & $73(41.7)$ \\
\cline { 2 - 3 } Educational degree & Married & $102(58.3)$ \\
\cline { 2 - 3 } & B.S & $173(98.3)$ \\
\hline \multirow{2}{*}{ Management experience } & M.S & $3(1.7)$ \\
\cline { 2 - 3 } & With experience & $3(1.7)$ \\
\hline \multirow{2}{*}{ Age (year) } & Standard deveriation & $28.54+-5.49$ \\
\cline { 2 - 3 } & The minimum- the maximum & $22-46$ \\
\hline \multirow{2}{*}{ Overtime (in a month) } & Standard deviation & $76.98+-19.31$ \\
\cline { 2 - 3 } & The minimum- the maximum & $20-120$ \\
\hline \multirow{2}{*}{ Work experience (year) } & Standard deviation & $5.09+-4.86$ \\
\cline { 2 - 3 } & The minimum- the maximum & $20-1$ \\
\hline \multirow{2}{*}{$\begin{array}{c}\text { The ratio of patients to the } \\
\text { nurses }\end{array}$} & Standard deviation & $9.55 \pm 3.06$ \\
\cline { 2 - 3 } & The minimum- the maximum & $4-20$ \\
\hline \multirow{2}{*}{ Table 1. Some Demographic Characteristics } \\
\hline \multirow{2}{|c}{}
\end{tabular}

\begin{tabular}{|c|c|c|}
\hline Nurses' Perception of Organizational Power & Frequency & \%age \\
\hline Poor (36-80) & 1 & 0.6 \\
\hline Average (81-125) & 82 & 46.9 \\
\hline Desirable (126-180) & 92 & 52.5 \\
\hline
\end{tabular}

Table 2. Distribution of Absolute and Relative Frequency and Level of Nurses' Perception of Nursing Organizational Power

\begin{tabular}{|c|c|c|c|c|}
\hline Variable & $\begin{array}{c}\text { Number } \\
\text { of Items }\end{array}$ & $\begin{array}{c}\text { Range of } \\
\text { Scores }\end{array}$ & Mean & SD \\
\hline Environmental pressure & 7 & $1-5$ & 3.50 & 0.53 \\
\hline Situation & 4 & $1-5$ & 3.65 & 0.63 \\
\hline Role play & 3 & $1-5$ & 3.79 & 0.61 \\
\hline Resources & 6 & $1-5$ & 3.34 & 0.68 \\
\hline Communication competency & 3 & $1-5$ & 3.53 & 0.64 \\
\hline The effectiveness of power in goal achievement & 4 & $1-5$ & 3.51 & 0.61 \\
\hline The qualification of superintendents & 4 & $1-5$ & 3.61 & 0.63 \\
\hline Power prospect & 5 & $1-5$ & 3.61 & 0.63 \\
\hline Nursing power & 36 & $1-5$ & 3.54 & 0.49 \\
\hline \multicolumn{2}{|c|}{ Table } \\
\hline 3. Nurses' Perception of the Componts
\end{tabular}

Table 3. Nurses' Perception of the Components of Nursing Organizational Power in the King Model

\begin{tabular}{|c|c|c|c|c|}
\hline \multirow{2}{*}{ Variable } & \multicolumn{2}{|c|}{$\begin{array}{c}\text { Work } \\
\text { Experience }\end{array}$} & \multicolumn{2}{|c|}{ Age } \\
\cline { 2 - 5 } & $\mathbf{P}^{*}$ & $\mathbf{R}$ & $\mathbf{P}$ & $\mathbf{R}$ \\
\hline Environmental pressure & 0.372 & -0.068 & 0.300 & -0.080 \\
\hline Position & 0.009 & -0.198 & 0.002 & -0.232 \\
\hline Roleplay & 0.255 & -0.087 & 0.250 & -0.088 \\
\hline Resources & 0.052 & -0.147 & 0.032 & -0.164 \\
\hline Communication qualification & 0.520 & -0.049 & 0.395 & -0.065 \\
\hline Effectivenessof power in facilitating achievement of goals & 0.318 & -0.076 & 0.283 & -0.083 \\
\hline The qualification of superintendents' supervision & 0.416 & -0.062 & 0.120 & -0.119 \\
\hline Powerprospect & 0.065 & -0.140 & 0.068 & -0.140 \\
\hline Nursingpower & 0.079 & -0.134 & 0.042 & 0.155 \\
\hline
\end{tabular}

Table 4. Relationship between Some Demographic Characteristics and Components of the Organizational Power of the Nursing Profession

\begin{tabular}{|c|c|c|c|c|c|c|}
\hline & & \multirow{2}{*}{ Average } & \multirow{2}{*}{$\begin{array}{l}\text { Standard } \\
\text { Deviation }\end{array}$} & \multicolumn{3}{|c|}{ Statistics } \\
\hline & & & & $t$ & df & $\mathbf{p}$ \\
\hline \multirow{2}{*}{ Marital status } & Single & 128.15 & 17.51 & \multirow{2}{*}{0.24} & \multirow{2}{*}{137} & \multirow{2}{*}{0.80} \\
\hline & Married & 127.47 & 18.41 & & & \\
\hline \multirow{2}{*}{ Training } & Yes & 126.89 & 17.97 & \multirow{2}{*}{-0.76} & \multirow{2}{*}{160} & \multirow{2}{*}{0.44} \\
\hline & No & 130 & 18.52 & & & \\
\hline \multirow{2}{*}{ Education } & Bachelor & 127.61 & 17.91 & \multirow{2}{*}{-0.80} & \multirow{2}{*}{173} & \multirow{2}{*}{0.42} \\
\hline & Masters & 136 & 25.11 & & & \\
\hline \multirow{2}{*}{ Income } & Yes & 136.22 & 17.43 & \multirow{2}{*}{2.39} & \multirow{2}{*}{173} & \multirow{2}{*}{0.01} \\
\hline & No & 126.53 & 17.80 & & & \\
\hline \multirow{2}{*}{ Management } & Yes & 105 & 24.06 & \multirow{2}{*}{-2.29} & \multirow{2}{*}{172} & \multirow{2}{*}{0.02} \\
\hline & No & 128.16 & 17.75 & & & \\
\hline \multirow{5}{*}{ Recruitment } & Official & 118.86 & 19.67 & \multirow{5}{*}{$F=1.60$} & \multirow{5}{*}{$170 \& 4$} & \multirow{5}{*}{0.175} \\
\hline & Contractual & 124.25 & 16.81 & & & \\
\hline & A pledge & 130.20 & 28.80 & & & \\
\hline & A company & 129.94 & 14.25 & & & \\
\hline & A plan & 129.60 & 17.90 & & & \\
\hline
\end{tabular}

Table 5. Comparison of Mean Score of Nurses' Perception

Based on Demographic Variables

Following the examination of the eight subsets of power in the King model and the rating method set by Sieloff and King, the results showed that the highest score was related to the role play and the position of the nursing group, which was 
$3.0 \pm 79.6$ and $0.0 \pm 65.63$ respectively. The lowest score was

for the resource and environmental factors, which was $3.34 \pm$ 0.68 and $3.50 \pm 0.33$, respectively. As for the qualification of the superintendents and the power prospect, the nurses were rated $3.61 \pm 0.63$ (Table 3 ).

Examining the relationship between the demographic characteristics and the nurses' perception of the organizational power (Table 4) unveiled the inverse relationship of age and work experience with the position subsets. As age and work experience increase, nurses' perception of the field decreases, and younger nurses have a better perception. There is also a significant and inverse relation between age and total score of nursing power. In other words, nurses' perception of organizational power decreases as they get older. No significant relationship was, however, found between the other areas of organizational power with age and work experience. The scores of the items of the organizational power questionnaire are listed in Table 4.

Our comparison of the mean scores of nurses' perceptions based on demographic variables showed that nurses, who were satisfied with their income, had better and more positive perceptions than nurses that were not satisfied. Besides, nurses with no management experience had a better perception of organizational power than nurses with management experience (Table 5).

\section{DISCUSSION}

Based on the assessment of nurses' perceptions of organizational power using SKAGPO questionnaire, most nurses had a good and moderate understanding of organizational power. In this regard, the study conducted by Valizadeh et al. to assess nurses' perceptions of organizational power showed that the majority of nurses had an average and desirable understanding. The study by Homayoune et al. on nurses' perception of organizational authority indicated the moderate perception of nurses in this area,(21) and the study by Wynne et al. in Australia on nurses' perceptions of organizational power showed that nurses had a moderate perception.(22) These findings are in line with the results of our study. Asadzandi et al also reported that nurses had a relatively high perception of their managers' empowering behaviour.(23) Similar findings by Wilson and Laschinger showed that nurses had a relatively high understanding.(24) The study by Zaimie Kermanshahi showed that $72.2 \%$ of executives were highly empowered. (25) The study by Bassaran et al. also revealed that $44 \%$ of nurses believed they had organizational power and only $34 \%$ had legal and informative power.(26) The results of this study did not comply with the current study, which can be attributed to the cultural differences, differences in the power structure, the study method and the sample size. This is because Bassaran' study was conducted on Turkish nurses with a different culture than Iranian nurses and the sample size was also larger. The results of the investigation by Ahadi Nejad et al. showed that perceived organizational justice is below average because the participants considered justice to be undesirable.(27) However, the findings reported by Bohluli et al. did not confirm this conclusion.(28) This difference in the results could be due to the difference in the management styles of the study cases. In our study, the lowest score was related to resources of power and environmental control by nurses. Besides, previous studies suggest that a lack of adequate resources, a lack of nursing staff, and a lack of sufficient resources for nurses are among the decisionmaking determinants in taking care of patients and determine powerlessness and inefficiency of nurses. (29) In the study by Valizadeh et al., most nurses had a limited understanding of the sources of power and environmental factors, which was in line with the results of this study. Moreover, the reports by Hinestala showed nurses' limited understanding of the role of resources in organizational power,(30) which is consistent with these findings. However, the study by Ascahinean revealed nurses' good understanding of the role of resources in gaining power, suggesting that they give high priority to the resources. (31) This fining is not in line with the results of the study mentioned above due to structural differences in power resources. Concerning the efficiency of communication, which plays an essential role in increasing the confidence of nurses in the workplace and increasing the sense of power of nurses in caregiving,(29) the results of this study mirrored nurses good understanding of this category. The study by Valizadeh et al. showed that most nurses had a limited understanding of the effectiveness of communication in nursing, which is not consistent with the results of this study. According to the study by Atri and Hinestala, nurses had no proper understanding of the power of communication in the nursing profession, $(30,31)$ which is not in line with the results of this study. As regards the position and role playing nursing, our results showed that nurses had the greatest understanding of these factors. In the study by Valizadeh et al., nurses had a moderate understanding of the position of the nursing group as part of the care system, which is not consistent with the results mentioned above. Concerning the effect of power on the attainment of goals, the results indicated that nurses had a moderate understanding, which contradicts the findings reported by Valizadeh et al., who reported that nurses had the highest understanding of their goals. Furthermore, the study by Atrium and Ruston did not confirm the results of our study. $(32,33)$ This lack of compliance can be attributed to the difference in the study methods, sample size, and cultural settings. In the study by Adib Hajbagheri, which confirmed the results of this study, power was a barrier to the attainment of organizational goals.(34) In the present study, younger and less experienced nurses had a better understanding of organizational power. In the study by Valizadeh et al., younger and less experienced nurses had a better understanding of the subsets of the power of environmental pressure and the role and qualification of the nursing supervision. The other areas of organizational power had no significant relationship with age and work experience, which does not comply with our findings. In a study by Curie Leesl et al., younger and less experienced nurses had a positive attitude toward the organizational power of nursing and its subsets, while older nurses considered changes resulting from organizational power in nursing to be threats and rejected them.(35) These results are not in line with the results of this study. However, a study conducted in Turkey in 2010 showed that more experienced nurses had better 
understanding and control over the monitoring, collaboration and communication tasks in the organization.(36) These findings are not consistent with the results of this study. The results of the aforesaid study indicated that nurses who were satisfied with their income level had a better understanding of organizational power than nurses who were not satisfied with their income. Besides, nurses with no management experience had a better perception than nurses with management experience. The findings reported by Nick Peima et al. (2005) showed that when employees can control and support the staff, the staff will be more motivated to play their role.(37) According to the results of our study, income and material rewards can determine the increase in the sense of power among nurses.

\section{CONCLUSIONS}

Based on the results of this study, which revealed nurses' desirable perception of organizational power and the effect of power on nurses' job motivation, it is suggested to give priority to the power and proper understanding of nurses as well as their proper distribution in organizations, especially in hospitals. It is also suggested to set the scene for nurses to be more empowered. It is, however, necessary to set the scene for nurses to increase their awareness of the organizational power and its effects on the quality of health care. Furthermore, nursing frameworks and models should be considered as components of an appropriate method for increasing nurses' perception of organizational power. If necessary, trainings at the hospital level can be provided to apply the management styles suiting the business of officials and staff.

\section{ACKNOWLEDGEMENT}

This study is an excerpt from a master's thesis on $\mathrm{f}$ Paediatric Nursing at Tabriz Nursing and Midwifery Faculty. Researchers express their gratitude to the vice president of research and the nursing and midwifery faculty for their financial support as well as the honourable director and manager of the nursing services at Shahid Motahari Hospital and all the nurses who participated in this study.

\section{REFERENCES}

[1] Mohammadi A, Pourvaghaz AV. Thinking styles with power supplies, school administrators. Journal of New Approaches in Educational Administration 2013;4(3):1138-70. [Persian]

[2] Torghabe KE. Determine the sources of power management and its relationship to the level of preparedness of staff. [Master's thesis] Physical Education 2004. [Persian]

[3] Fayazi HRSM. The relationship between power perception and organizational policies with employee commitment and performance. Specialized social studies study. Humanities and Management Eighth 2009;(29).
[4] Benoit-Barné C, Cooren F. The accomplishment of authority through presentification: how authority is distributed among and negotiated by organizational members. Management Communication Quarterly 2009;23(1):5-31.

[5] Dunham R. Individual and organizational strategies for coping with organizational power. Academy of Management 2002;21:73-80.

[6] Dargahi H. Organizational behavior: ethical or unethical. Iranian Journal of Medical Ethics and History of Medicine 2013;5(7):1-14.

[7] Ponte PR, Glazer G, Dann E, et al. The power of professional nursing practice-an essential element of patient and family centered care. The Online Journal of Issues in Nursing 2007;12(1):4.

[8] Bularzik AM, Tullai-Mcguinness S, Sieloff CL. Nurse's perceptions of their group goal attainment capability and professional autonomy: a pilot study. Journal of Nursing Management 2013;21(3):581-90.

[9] Tang TL-P, Sarsfield-Baldwin LJ, et al. Distributive and procedural justice as related to satisfaction and commitment. SAM Advanced Management J 1996;61:2531.

[10] Mahbobkhah F, Beigzadeh Y. The structural model of personality traits of nurses' entrepreneurship based on the sources of power of managers and the role of administrative mediator of organizational justice. Quarterly Journal of Nursing Medicine 2018;6(3 \& 4):1727.

[11] Valizadeh S, Zamanzadeh V, Ebrahimi $H$, et al. Assessment of nurses' perceptions of nursing power based on King Model. Quarterly Journal of Nursing Management 2013;1(4):28-35.

[12] Kirkman BL, Chen G, Farh J-L, et al. Individual power distance orientation and follower reactions to transformational leaders: a cross-level, cross-cultural examination. Academy of Management Journal 2009;52(4):744-64.

[13] Rahimaghaee F, Nayeri D, Mohammadi E. Iranian nurses perceptions of their professional growth and development. OJIN: The Online Journal of Issues in Nursing 2010;16(1):10.

[14] McGibbon E, Peter E, Gallop R. An institutional ethnography of nurses' stress. Qualitative Health Research 2010;20(10):1353-78.

[15] Laschinger HKS, Havens DS. The effect of workplace empowerment on staff nurses' occupational mental health and work effectiveness. Journal of Nursing Administration 1997;27(6):42-50.

[16] Alligood MR. Nursing Theory-E-Book: utilization \& application. $5^{\text {th }}$ edn. Elsevier Health Sciences 2013.

[17] Sieloff CL. Measuring nursing power within organizations. Journal of Nursing Scholarship 2003;35(2):183-7.

[18] Heidary A, Mazlom R, Ildarabadi E. Nursing's position in health care delivery system in Iran. Iran J Nurs Res 2012;7(25):37-44.

[19] Sieloff CL, Frey MA. The theory of group power within organizations-evolving conceptualization within King's conceptual system. Middle range theory development: Using King's conceptual system. Springer Publishing Company, 2007: p. 196-214. 
[20] D'Antonio P, Connolly C, Wall BM, et al. Histories of nursing: the power and the possibilities. Nursing Outlook 2010;58(4):207-13.

[21] Homayouni F, Dabbaghi F, Jalal EJ, et al. The relationship between Nurses' perception of their head Nurses' empowering behaviors and their own work empowerment in teaching hospitals of Khorram Abad, 2003. Iran Journal of Nursing 2004;16(36):34-9.

[22] Wynne R. Ten Australian ICU nurses' perceptions of organisational restructuring. Australian Critical Care 2004;17(1):16-8, 20-4.

[23] Asad ZM, Ebadi A, Karami ZA, et al. The relationship between nurse's perception of their head nurses empowerment behaviors and their own work effectiveness. 2007.

[24] Laschinger HK, Wong C, McMahon L, et al. Leader behavior impact on staff nurse empowerment, job tension and work effectiveness. Journal of Nursing Administration 1999;29(5):28-39.

[25] Kermanshahi Z, Hajizadeh E. The effect of retraining management skills of nursing managers on the empowerment of nursing personnel, Journal of Zanjan University of Medical Sciences 2005;21(50)13-14.

[26] Basaran S, Duygulu S. Turkish nurses' assessments of their power and the factors that affect it. Journal of Nursing Management 2015;23(8):1039-49.

[27] Ahadinezhad B, Mohebifar R, Akbari A, et al. The relationship between employees' perception of organizational justice and their productivity in selected educational hospitals at Tehran University of Medical Sciences: 2011. Journal of Health 2015;6(2):202-10.

[28] Bohluly ZN, Alavi MY, Derakhshan MA. The effect of organizational justice on organizational citizenship behavior of the personnel of Islamic Azad University of
Tabriz. Productivity Management (Beyond Management) 2010;4(14):73-108.

[29] Bagheri MAH, Salsali M, Ahmadi F. Clinical decisionmaking: a way to professional empowerment in nursing. Iranian Journal of Medical Education 2003;3(2):3-13.

[30] Hintsala A. Autonomy anticipating career change in nursing. Female and male nurses 'assessment and comparison of decision-making, competency, importance of work and leadership in nursing. Kuopio: University of Kuopio, 2005.

[31] Asikainen P, Suominen T, Maenpa T, et al. Data exchange and shared care between different professional groups and organizations in social and health care in implementation of the regional reference database. Hoitotiede 2008;20:59-69.

[32] Attree M. Nursing agency and governance: registered nurses' perceptions. Journal of Nursing Management 2005;13(5):387-96.

[33] Ruston A. Interpreting and managing risk in a machine bureaucracy: professional decision-making in NHS Direct. Health, Risk \& Society 2006;8(3):257-71.

[34] Hagbaghery AM, Salsali M, Ahmadi F. A qualitative study of Iranian nurses' understanding and experiences of professional power. Human Resources for Health 2004;2(1):9.

[35] Corey-Lisle P, Tarzian AJ, Cohen MZ, et al. Healthcare reform. Its effects on nurses. Journal of Nursing Administration 1999;29(3):30-7.

[36] VJ. Manage role of job satisfaction. [MSc thesis] economic management Finland: Turku school of economics 2010.

[37] Nikpeyma N, Ashktorab T. Nurses' views about factors affecting the professional roles. J Health Promotion Management
2012;1(3):73-84. 